\title{
Pathological Evaluation of Anti-tumour Effects of Withaferin A against Experimentally Induced Mammary Tumour in Rats
}

\author{
K. Pratheepa* , C. Balachandran and R. Sridhar \\ Department of Veterinary Pathology, Madras Veterinary College, TANUVAS, \\ Chennai- 600 007, India \\ *Corresponding author
}

\begin{tabular}{l} 
Ke y w o r d s \\
DMBA, Mammary \\
tumours, Pathology, \\
$\begin{array}{l}\text { Rats, Tamoxifen, } \\
\text { Withaferin A }\end{array}$ \\
\hline Article Info \\
\hline $\begin{array}{l}\text { Accepted: } \\
10 \text { June } 2020 \\
\text { Available Online: } \\
\text { 10 August } 2020\end{array}$ \\
\hline
\end{tabular}

\section{A B S T R A C T}

\begin{abstract}
With the aim to explore the anti-tumour effect of Withaferin A in DMBA $(7,12-$ dimethylbenz[a]anthracene) induced mammary tumour in rats, seventy two female Sprague-Dawley rats were equally distributed to control, DMBA, tamoxifen and Withaferin A groups. Tamoxifen, which is widely used as first-line drug in the treatment of estrogen positive breast cancer was taken as standard for comparison. The study was conducted for a period of 16 weeks. DMBA ( $5 \mathrm{mg} / \mathrm{rat} / \mathrm{week} / \mathrm{per}$ os) at 4 weekly doses were used for tumour induction. Piloerection was noticed after DMBA administration. Tumour latency, location, incidence, frequency, size, volume and weight were recorded. Hundred per cent tumour formation in DMBA alone administered animal was observed. No metastasis was recorded. Abdominal glands were most frequently affected in all DMBA administered groups. Withaferin A group showed 17\% tumour inhibition and the number of tumours were almost equal to that of DMBA group. Higher incidence of carcinomas (65\%) and lower incidence of benign (35\%) mammary tumours were observed in Withaferin A group with maximum tumour frequency of seven tumours/rat when compared with tamoxifen group. Hence further investigations are required.
\end{abstract}

\section{Introduction}

Breast cancer being the most frequently diagnosed cancer in females, its metastatic state represents the second leading cause of death (Desantis et al., 2011). The incidence of breast cancer is increasing at alarming places in India, mainly in metropolitan cities, where 1out of 22 women is likely to suffer from breast cancer during their lifetime. Also, based on incidence breast cancer is becoming the number one in females pushing the cervical cancer to the second place (Murthy et al., 2009). Therefore, animal models of breast cancer are becoming great area of interest for studying etiology, prevention and treatment of cancer. Among the animal models, chemically induced rat models are the most widely used model to study the human mammary carcinogenesis due to shorter latency period, 
reproducibility and flexibility in isolation of tumour tissues during various stages of tumouriogenesis.

The prototypic polycyclic aromatic hydrocarbons (PAHs), 7,12-dimethylbenz[a] anthracene (DMBA) is most commonly employed carcinogen for mammary tumour induction in rodents (Russo and Russo, 1996) especially in outbred Sprague-Dawley (SD) rats. Because SD rats are most sensitive to DMBA and mammary gland is a major target organ for DMBA. In addition, this model is well known for the development of multiple mammary tumours that are morphologically heterogenous and hormone dependent, predominantly depending upon prolactin for growth (Russo et al., 1990).

Prevention is the best way to control breast cancer. Approximately $70 \%$ of breast cancers are estrogen receptor positive (ER- $\alpha$ ) cancers (Plaza-menacho et al., 2010). Selective estrogen receptor modulators (SERMs) like tamoxifen appears to be promising drug for prevention of breast cancer, but it is effective only against estrogen receptor positive $(\mathrm{ER}-\alpha)$ cancers and ineffective against estrogen receptor negative breast cancers. Moreover tamoxifen have other side effects including increased risk of uterine cancer, thromboembolism, cataracts and perimenopausal symptoms (Fisher et al., 1998 and Cuzik et al., 2002).

The major drawback of long term chemotherapy is the development of tumour resistance during classical treatments (Wong and Goodin, 2009).

Therefore identification of agents that can suppress the growth of both estrogen positive and negative breast cancer with less or no side effects becomes unavoidable. Natural products receive increased attention in recent years towards the discovery of novel chemopreventive and chemotherapeutic agents (Newman et al., 2003).

One such natural product is Withaferin A, derived from the medicinal plant Withania somnifera (also known as Ashwaganda, Indian ginseng or Winter cherry) and has been safely used for centuries in Indian ayurvedic medicine. Much of Ashwaganda's pharmacological activity has been atrributed to two main with anolides, Withaferin Aand Withanolide D. Withaferin A, a steroidal lactone, is mainly localized in the leaves of the shrub (Gajbhiye et al., 2015) and known to have anti-inflammatory, immunomodulatory, anti-tumour, anti-angiogenic and radiosensitizing effects with no systemic toxicity (Chowdhury and Neong, 1975, Bhattacharya, 2002 and Kamath et al., 1999).

Withaferin A structure resembles aromatic isothiocyanates, which are highly promising cancer chemopreventive constituents of cruciferous vegetables and it also has structural similarity to steroid backbone of estradiol, which functions as anti-estrogen by down regulating ER- $\alpha$ expression in human breast cancer cells (Zhang et al., 2011). The exact mechanism for its anti-cancer effect is still not clearly understood.

Chemoprevention studies in animal model system of carcinogenesis are a pre-requiste for chemotherapy testing in cancer patients. To the best of our knowledge, there are very few reports on protective effect of Withaferin A in chemically induced in vivo mammary carcinogenesis.

In the present study, DMBA initiated mammary tumour in SD rats is taken as a model to study the protective effect of Withaferin A, as an alternating agent in mammary carcinogenesis. 


\section{Materials and Methods}

\section{Chemicals}

Withaferin A was obtained as gratis from $\mathrm{M} / \mathrm{s}$. Nutricon Bioscience Pvt. Ltd., Kancheepuram district, Tamilnadu. 7,12Dimethylbenz[a]anthracene was obtained from M/s. Sigma Aldrich Inc., St. Louis, USA (D3254-1G, Lot No. SLBC8508V). Tamoxifen citrate was purchased from $\mathrm{M} / \mathrm{s}$. Khandelwal Laboratories Pvt. Ltd., Mumbai, India (Batch No. TTMA30605A \{Mamofen $10\})$.

\section{Animals}

The experiment was carried out with 72 virgin female Sprague-Dawley rats of 38 days old, weighing between 65 and 130 g. Rats, obtained from National Institute of Nutrition, Hyderabad, India, were housed at the rate of 3rats/polycarbonate cage with ad libidum access to pellet feed and reverse osmosis purified water. They were maintained in a controlled environment under standard conditions of temperature $\left(22 \pm 3^{\circ} \mathrm{C}\right)$ and humidity $(50 \pm 10 \%)$ with an alternating $12 \mathrm{~h}$ light/dark cycle. This animal experiment was carried out after the approval of Institutional animal ethical committee (IAEC), Madras Veterinary College (MVC), Chennai-07, India and as per the guidelines of Committee for the Purpose of Control and Supervision of Experimentation in Animals (CPCSEA), Government of India.

\section{Experimental design}

The rats were randomized into four groups (18rats/group) with mean body weight ( $\mathrm{g}$ ) variation not exceeding $10 \%$. All the treatments were initiated at the age of $43^{\text {rd }}$ day. Group 1 rats received basal diet and served as control. Rats of Group 2 (DMBA), 3 (DMBA+Tamoxifen) and 4 (DMBA+
Withaferin A) were administered with four doses of DMBA dissolved in olive oil at 5 $\mathrm{mg} / \mathrm{rat} /$ week by intragastric intubation. Rats of group 3 received daily oral doses of tamoxifen dissolved in gingelly oil at 100 $\mu \mathrm{g} / \mathrm{kg}$ body weight and group 4 received oral doses of Withaferin A dissolved in PBS $(\mathrm{pH}$ 7.4) at $16 \mathrm{mg} / \mathrm{kg}$ body weight thrice a week till the end of study for chemoprevention.

Physical examination and palpation of mammary glands was performed from 2 weeks after administration of the first dose of DMBA, to monitor mammary tumour appearance and growth. Tumour incidence, latency, location, frequency were recorded till the end of study period. Six rats from each group were euthanized on $30^{\text {th }}, 75^{\text {th }}$ and $120^{\text {th }}$ day by exposing to gradually rising concentration of carbondioxide $\left(\mathrm{CO}_{2}\right)$ gas in a transparent anesthetic chamber. A detailed post mortem examination was conducted on sacrificed rats. All the internal organs were examined for any evidence of metastasis.

\section{Gross \& Histopatholigical studies}

Gross pathology of the mammary tumour was recorded. The two largest diameters $(\mathrm{mm})$ of each tumour were measured using a digital caliper (M/s Mitutoyo Corporation, Japan) and the tumour volume $\left(\mathrm{mm}^{3}\right)$ was calculated by $\left(a \times b^{2} / 2\right)$, where ' $a$ ' is larger diameter and ' $b$ ' is smaller diameter (Carlsson et al., 1983). Tumour weight $(\mathrm{g})$ was recorded using digital weighing balance. The excised mammary tumour samples were fixed in $10 \%$ neutralbuffered formalin and embedded in paraffin wax.

Histopathological examination was performed on $5 \mu \mathrm{m}$ - thick paraffin sections stained with haematoxylin and eosin (H\&E). Mammary tumours were classified histologically according to the criteria outlined by Mann et al., (1996) and Russo and Russo (2000) by 
utilizing double-headed Olympus BX-51 microscope.

\section{Statistical analysis}

The data generated from different parameters of the experimental study were subjected to one-way analysis of variance (ANOVA) test using SPSS software version 20 for windows.

\section{Results and Discussion}

Incidence and mean latency, frequency, tumour size, tumour volume and tumour weight of DMBA induced mammary tumour in control and experimental rats were presented in Table 1.

On oral administration of four doses of DMBA starting at the age of 43 days, $100 \%$ tumour induction in DMBA alone group and highest number of tumours per animal were recorded which was similar to the findings of Zimniski and Warren (1993). The susceptibility of the mammary gland to DMBA carcinogenesis is strongly age dependent being maximal between the ages of 45 and 60 days, during which the mammary gland exhibits a high density of highly proliferating terminal end buds (TEBs). The mammary tumours in rats arise in the epithelium of the TEBs, which are comparable structures to the terminal ductal lobular units in the human breast.

Tumour incidence was $72 \%$ in tamoxifen concurred with the findings of Zimniski and Warren (1993) who reported that coadministration of tamoxifen ( $\mathrm{s} / \mathrm{c})$ and DMBA (per os) resulted in a dramatic reduction in the number of tumours, but ultimately 45-70\% tamoxifen treated rats developed tumours. Withaferin A treated rats showed $84 \%$ tumour incidence, which was concurrent with the findings of Hahm et al., 2013 who had reported that Withaferin $\mathrm{A}$ reduced the tumour burden but couldn't reduce the tumour incidence.

Significantly $(\mathrm{P}<0.05)$ longer latency period was observed in the DMBA+tamoxifen group than DMBA and DMBA+Withaferin A group. The first palpable mammary tumour appeared on $4^{\text {th }}$ week after first dosing of DMBA in all the experimental groups, among the tumour bearing rats of DMBA, DMBA+tamoxifen and DMBA+Withaferin A groups $83 \%, 62 \%$ and $93 \%$ respectively developed its first tumour in $4^{\text {th }}$ week. Rest of the $17 \%$ of DMBA and $7 \%$ of DMBA+Withaferin A group rats developed their first tumour on $9^{\text {th }}$ to $12^{\text {th }}$ weeks. However in DMBA+tamoxifen group, 23\% of rats developed their first tumour $9^{\text {th }}$ to $12^{\text {th }}$ weeks and $15 \%$ of rats developed their first tumour even during $16^{\text {th }}$ to $17^{\text {th }}$ week of the study.

Additional tumours continued to appear till 17 th week in all the experimental groups with a maximum of 5,3 and 7 tumours/rat in the DMBA, DMBA+tamoxifen and DMBA+Withaferin A groups respectively. The total number of tumours in DMBA+Withaferin A $(n=43)$ was slightly lower than that of DMBA $(n=46)$ group.

Location of DMBA-induced mammary tumours in experimental rats was presented in Table 2. Irrespective of the treatment, abdominal glands were the most frequently affected glands. To the best of our knowledge, there is no report on higher incidence of mammary tumour in the abdominal glands and this might be due to the difference in the susceptibility of mammary gland to carcinogen (Russo and Russo, 1996). 
Table.1 Incidence and mean $( \pm \mathrm{SE})$ latency (days), frequency, tumour size $(\mathrm{mm})$, tumour volume $\left(\mathrm{mm}^{3}\right)$ and tumour weight $(\mathrm{g})$ of DMBA induced mammary tumour in tamoxifen and Withaferin A treated SD rats

\begin{tabular}{|c|c|c|c|c|}
\hline Parameters & Control & DMBA & $\begin{array}{c}\text { DMBA+ } \\
\text { Tamoxifen }\end{array}$ & $\begin{array}{c}\text { DMBA+ } \\
\text { Withaferin A }\end{array}$ \\
\hline $\begin{array}{l}\text { Tumour incidence } \\
(\%)\end{array}$ & - & 100 & 72 & 84 \\
\hline $\begin{array}{l}\text { Number of tumour } \\
\text { bearing animals }\end{array}$ & - & 18 & 13 & 15 \\
\hline $\begin{array}{l}\text { Total number of } \\
\text { tumours }\end{array}$ & - & 46 & 23 & 43 \\
\hline $\begin{array}{l}\text { Tumour latency } \\
\text { (week) }\end{array}$ & - & $28.61^{\mathrm{a}} \pm 4.22$ & $45.46^{b} \pm 9.40$ & $27.67^{\mathrm{a}} \pm 3.60$ \\
\hline Tumour frequency & - & $2.56 \pm 0.32$ & $1.69 \pm 0.17$ & $2.80 \pm 0.49$ \\
\hline $\begin{array}{l}\text { Tumour size, a } \\
(\mathrm{mm})\end{array}$ & - & $22.40^{\mathrm{a}} \pm 2.25$ & $13.74^{b} \pm 2.30$ & $22.40^{\mathrm{a}} \pm 1.92$ \\
\hline $\begin{array}{l}\text { Tumour size, b } \\
(\mathrm{mm})\end{array}$ & - & $15.38 \pm 1.56$ & $10.94 \pm 1.36$ & $16.07 \pm 1.63$ \\
\hline $\begin{array}{l}\text { Tumour volume } \\
\left(\mathbf{m m}^{3}\right)\end{array}$ & - & $5333.75 \pm 1306.93$ & $1285.70 \pm 512.65$ & $5990.45 \pm 1663.94$ \\
\hline Tumour weight (g) & - & $5.58 \pm 1.43$ & $3.47 \pm 1.67$ & $4.58 \pm 0.96$ \\
\hline
\end{tabular}

Means with same superscripts between the column do not differ from each other $(\mathrm{P}<0.05)$ a- larger diameter, $b$ - smaller diameter

Table.2 Location of mammary tumour in DMBA, DMBA+tamoxifen and DMBA+Withaferin A treated SD rats

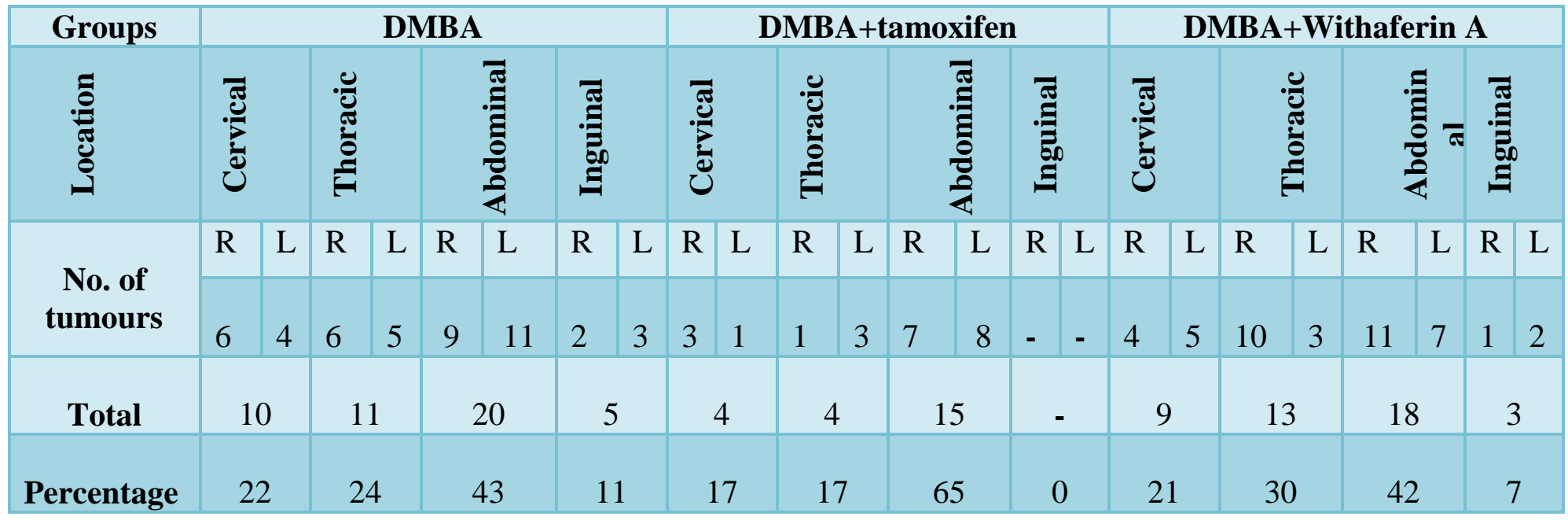


Table.3 Nature of DMBA induced tumours in different glands in tamoxifen and WithaferinA treated SD rats

\begin{tabular}{|c|c|c|c|c|c|c|c|c|}
\hline \multirow[t]{2}{*}{ Location } & \multicolumn{2}{|c|}{ DMBA } & \multicolumn{2}{|c|}{ DMBA+tamoxifen } & \multicolumn{2}{|c|}{$\begin{array}{c}\text { DMBA }+ \text { Withaferin } \\
\text { A }\end{array}$} & \multirow[t]{2}{*}{ Total } & \multirow[t]{2}{*}{$\begin{array}{l}\text { Per } \\
\text { cent }\end{array}$} \\
\hline & Benign & Malignant & Benign & Malignant & Benign & Malignant & & \\
\hline Cervical & 6 & 4 & 1 & 3 & 4 & 5 & 23 & 21 \\
\hline Thoracic & 2 & 9 & - & 4 & 3 & 10 & 28 & 25 \\
\hline Abdominal & 11 & 9 & 14 & 1 & 8 & 10 & 53 & 47 \\
\hline Inguinal & 1 & 4 & - & - & - & 3 & 8 & 7 \\
\hline Total & 20 & 26 & 15 & 8 & 15 & 28 & 112 & \\
\hline Per cent & 43 & 57 & 65 & 35 & 35 & 65 & & \\
\hline
\end{tabular}

Fig.1 Gross pathology (A): $75^{\text {th }}$ day - Comparison of mammary growth between different groups. (B): Ulcerated and haemmorhagic right thoracic mammary growth. (C): DMBA + Withaferin A- $75^{\text {th }}$ day - Variable sized multilobulated mammary growth with necrosis. (D): DMBA + WithaferinA- $120^{\text {th }}$ day - Cut section showing necrosis and haemorrhage

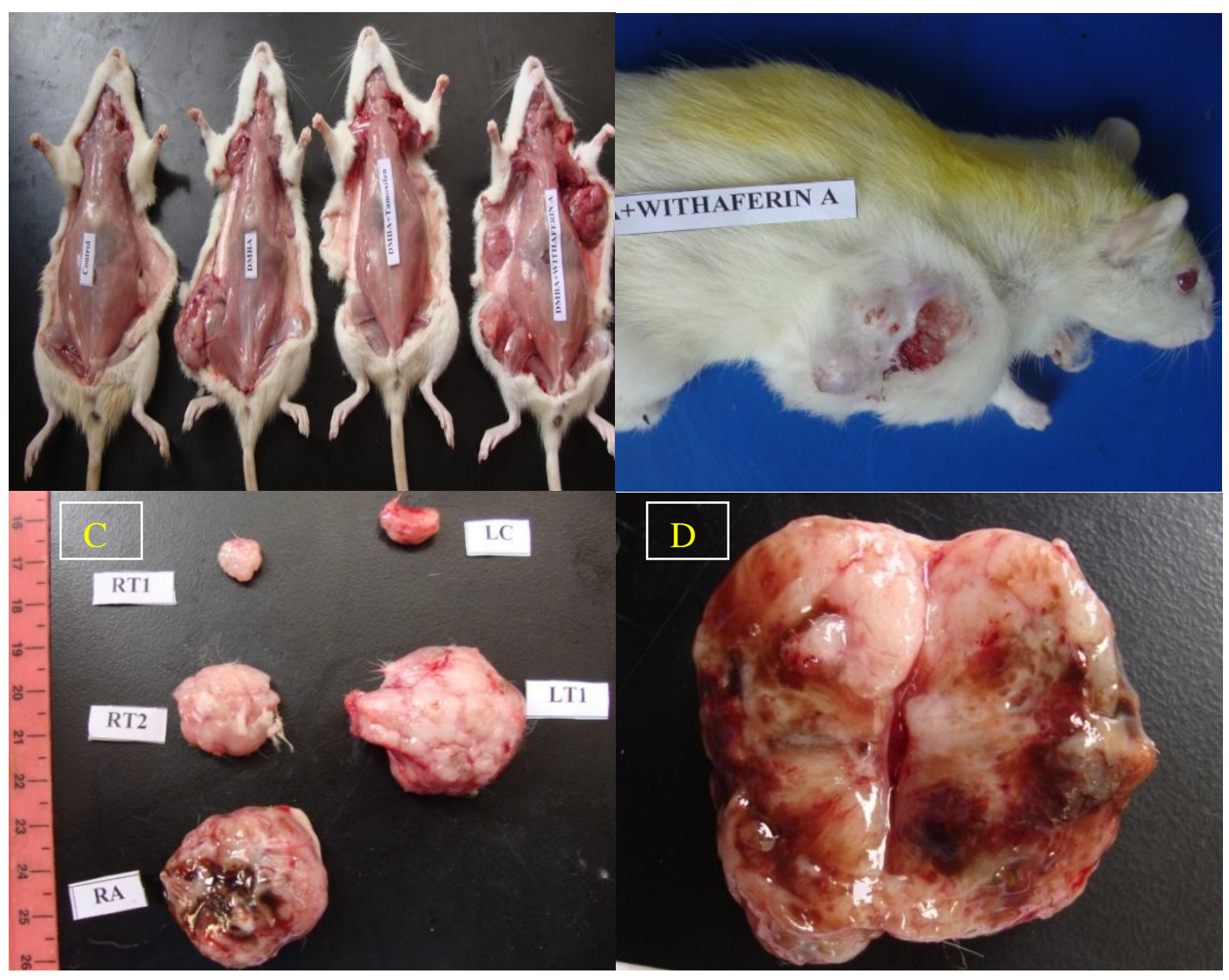


Fig.2 Histopathology (A) DMBA + Withaferin-A $120^{\text {th }}$ day - Secretory adenocarcinoma, H\&E Bar $=100 \mu \mathrm{m},(\mathrm{B}) \mathrm{DMBA}+$ Withaferin A $-120^{\text {th }}$ day - Cyst adenocarcinoma, H\&E Bar=100 $\mu \mathrm{m}$, (C) DMBA + Tamoxifen $-120^{\text {th }}$ day - Comedo carcinoma, H\&E Bar $=50 \mu \mathrm{m}$, (D) DMBA $-120^{\text {th }}$ day - Adenocarcinoma-Mitosis, H\&E Bar=10 $\mu \mathrm{m}$, (E) DMBA + Withaferin A- 75 ${ }^{\text {th }}$ day Tubular adenocarcinoma- Mast cell infiltration, H\&E Bar $=10 \mu \mathrm{m}$, (F) DMBA - $120^{\text {th }}$ day -

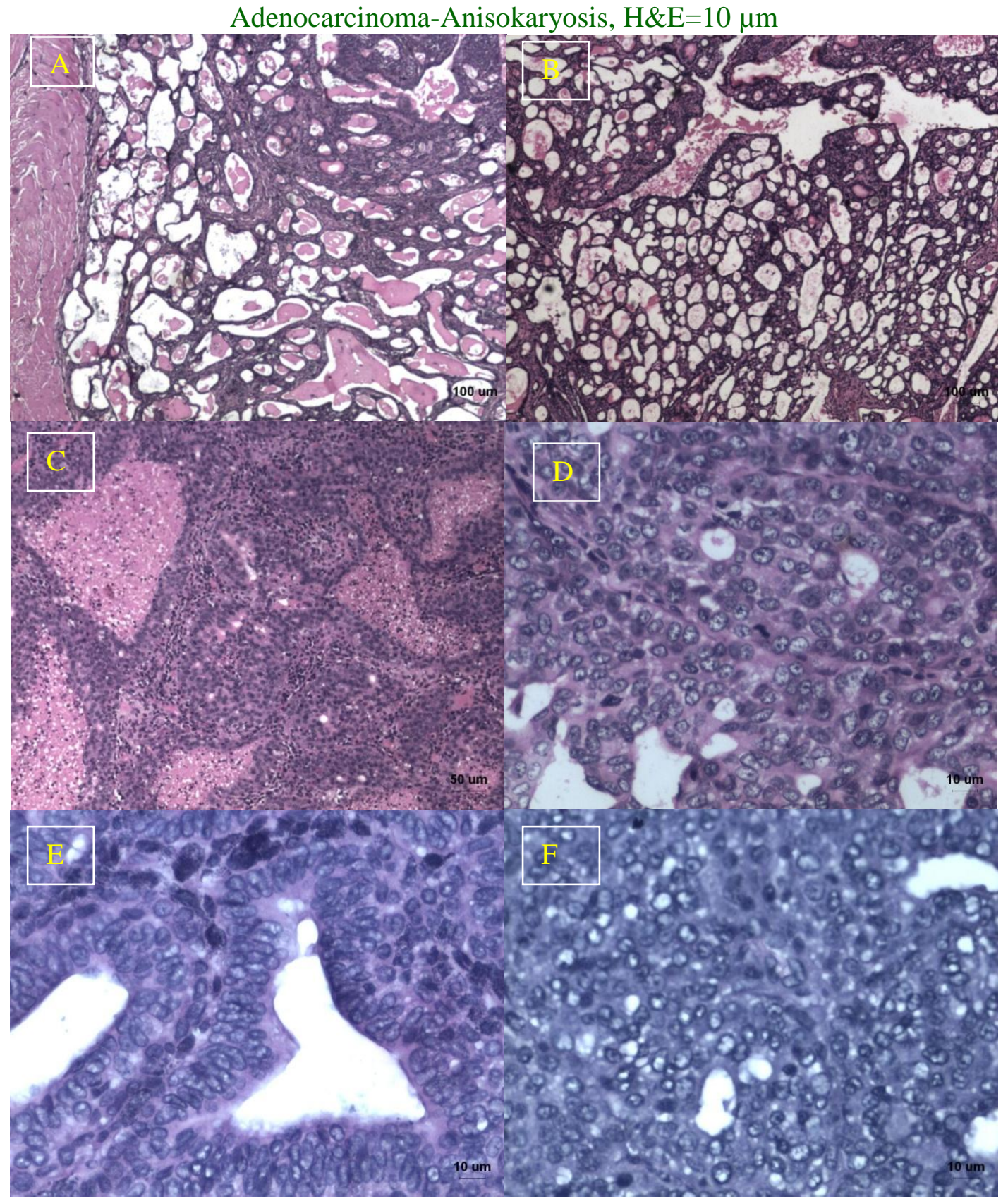

Grossly, mammary tumours in all the experimental groups were grayish-white in colour, single to multilobulated, circumscribed and located subcutaneously and non-adherent to the subcutis except in five cases. Few tumours in DMBA and Withaferin A group were ulcerated, necrotic and haemorrhagic (Fig.1A-D). On incision, 
the tumours were soft or firm in consistency, grayish white and showed areas of necrosis, greasy and in some tumours slimy greenish tinged fluid oozed out. No metastatic lesions were observed. The gross pathological observations were in agreement with Russo and Russo (2000), Costa et al. (2002) and Thompson and Singh (2000).

In addition, the highest incidence of malignant (65\%) and the lowest incidence of benign $(35 \%)$ tumours were observed in DMBA+Withaferin A when compared with DMBA $(43 \% \& 57 \%)$ and DMBA+ Tamoxifen $(35 \% \& 65 \%)$ groups as shown in Table 3.

In this study, different patterns of adenocarcinomas were observed (Fig 2A-F) in all experimental group. The most important factor in determining the incidence of adenocarcinomas is the number of TEBs existing in the mammary gland by the time of DMBA administration (Sinha and Dao, 1975). Since DMBA was administered at the age of 43 days, all the mammary carcinomas in the present study were adenocarcinomas which agreed with the findings of Costa et al., (2002) who reported that most of the DMBA induced tumours were malignant and epithelial in nature. Tamoxifen treated rats showed $28 \%$ tumour inhibition. Out of 23 tumours in 13 tumour bearing animals, $65 \%$ were benign $(n=15)$ and $35 \%$ were malignant tumours $(n=8)$ with maximum of 3 tumours/animal. No tumours were found in inguinal gland. Significant decrease in the larger diameter $(\mathrm{mm})$ of tumour size in tamoxifen and numerically less tumour volume $\left(\mathrm{mm}^{3}\right)$ was observed in comparison with DMBA and Withaferin A groups . These findings suggestive of tumour regression and agreed with Osborne et al., (1983) and Sutherland et al., (1983) who provided supportive evidence that tamoxifen was tumoristatic rather than a tumoricidal agent.
In conclusions, the study revealed that Withaferin $A$ at the dose rate of $16 \mathrm{mg} / \mathrm{kg}$ body weight/thrice a week/per os for 16 weeks did not reduce mammary tumour incidence, frequency or number of tumours and carcinomas compared to that of standard drug tamoxifen. The results in the present study questions the antitumour potential of Withaferin A and were contrary to the findings of other studies which proved the antitumour effect of Withaferin $\mathrm{A}$ in various cancer cell lines and animal tumour models. Hence further investigations required.

\section{Acknowledgement}

We sincerely thank and acknowledge the intense support provided by Late. Dr. S.M. Sakthivelan, M.V.Sc through out the study. We also acknowledge M/s. Nutricon Bioscience Pvt. Ltd., Tamil Nadu, India for providing Withaferin A as gratis.

\section{References}

Bhattacharya SK, Bhattacharya D, Sairam K and Ghosal S. 2002.Effect of Withania somnifera glycowithanolides on a rat model of tardive dyskinesia. Phytomedicine, 9: 167-170.

Carlsson G, Gullberg B and Hafstrom L. 1983.Estimation of liver tumour volume using different formulas- An experimental study in rats.J Cancer Res Clin., 105:20-23.

Costa I, Solanas $M$ and Escrich E. 2002.Histopathologic characterization of mammary neoplastic lesions induced with 7, 12-dimethylbenz(a)anthracene in the rat. Arch Pathol Lab Med 126: 915-927.

Chowdhury K and Neogy RK. 1975. Mode of action of Withaferin A and Withanolide D. BiochemPharmacol., 24: 919-920

Cuzik J, Forbes J, Edwards R, Baum M, Cawthorn S, Coates A, Hamed A, 
Howell A and Powles T. 2002. First results from the International Breast Cancer Intervention study (IBIS-I): a randomized prevention trial. Lancet, 360: 817-820.

Desanti C, Siegel R, Bandi P and Jemal A. 2011.Breast cancer statistics. CA: A Cancer. J. Clin., 61: 408-418.

Fisher B, Costantino JP, Wickerham DL, Redmond CK, Kavanah M, Cronin WM, Vogel V, Robidoux A, Dimitrov N, Atkins J, Daly M, Wieland S, Tan Chiu E, Ford L and Wolmark N. 1998. Tamoxifen for prevention of breast cancer: report of the national surgical adjuvant breast and bowel project P-1 study. J Natl Cancer Inst., 90: 13711388.

Gajbhiye, N.A., Makasana, J. and Kumar S. 2015. Accumulation of three importanat bioactive compounds in different plant parts of Withania somnifera and its determination by the LC-ESI-MS-MS (MRM) method. J. Chromatogr. Sci., 53: 1749-1756.

Hahm, ER. And Singh SV. 2013. Withaferin A-induced apoptosis in human breast cancer cells is associated with suppression of inhibitor of apoptosis family protein expression. Cancer Lett., 334: 101-108.

Kamath R, Rao BSS and Devi PU. 1999. Response of a mouse fibrosarcoma to Withaferin A and radiation. Pharm Pharmacol Commun., 5: 287-291.

Mann PC, Boorman GA, Lollini LO, McMartin DN and Goodman DG. 1996. Proliferative lesions of the mammary gland in rats. Guides for Toxicologic Pathology (2):1-7.

Murthy NS, Chaudary K, Nadayil D, Agarwal UX and Saxena S. 2009.Changing trends in incidence of breast cancer: Indian scenario. Indian $J$ Cancer, 46: 73-74.

Newman DJ, Gragg GM and Snader KM.
2003. Natural products as source of new drugs over the period 1981-2002.J Nat Prod., 66: 1022-1037.

Osborne CK, Boldt DH, Clark GM and Trent JM. 1983. Effects of tamoxifen on human breast cancer cell cycle kinetics: Accumulation of cells in early $\mathrm{G}_{1}$ phase. Cancer Res., 43: 3583-3585.

Plaza-Menacho I, Morandi A, Robertson D, Pancholi S, Drury S, Dowsett M, Martin LA and Isacke CM. 2010. Targetting the receptor tyrosine kinase RET sensitizes breast cancer cells to tamoxifen treatment and reveals a role for RET in endocrine resistance. Oncogene, 29: 4648-4657.

Russo J, Gusterson BA, Rogers AE, Russo IH, Wellings SR and Zweiten MJV. 1990. Biology of disease: Comparative study of human and rat mammary tumorigenesis. Lab Invest 62: 224-278.

Russo IH and Russo J. 1996. Mammary gland neoplasia in long-term rodent studies. Environ Health Perspect 104: 938-967.

Russo J and Russo IH. 2000. Atlas and histologic classification of tumours of the rat mammary gland. J Mammary Gland Biol5:187-200.

Sinha DK and Dao TL. 1975. Brief communication: Site of origin of mammary tumours induced by 7,12 dimethylbenz(a)anthracene in the rat. $J$. Natl. Cancer Inst., 54: 1007-1009.

Sutherland RL, Green MD, Hall RE, ReddelRR and Taylor IW. 1983. Tamoxifen induces accumulation of MCF-7 human mammary carcinoma cells in the G0/G1, phase of the cell. Eur. J. Cancer Clin.Oncol.,19: 615-621.

Thompson HJ and Singh M. 2000. Rat models of premalignant breast disease. $J$. Mammary Gland BiolNeoplasia.5: 409420.

Wong ST and Goodin S. 2009. Overcoming drug resistance in patients with metastatic breast cancer. 
Pharmacotherapy, 29: 954-965.

Zhang X, Mukerji R, Samadi AK and Cohen

MS. 2011.Downregulation of estrogen receptor -alpha and rearranged during transfection tyrosine kinase is associated with Withaferin A-induced apoptosis in MCF-7 breast cancer cells. BMC Complement Altern. Med., 6: 84.

Zimniski SJ and Warren RC. 1993. Induction of tamoxifen dependent rat mammary tumours. Cancer Res 53: 2937-2939.

\section{How to cite this article:}

Pratheepa, K., C. Balachandran and Sridhar, R. 2020. Pathological Evaluation of Anti-tumour Effects Withaferin A against Experimentally Induced Mammary Tumour in Rats. Int.J.Curr.Microbiol.App.Sci. 9(08): 125-134. doi: https://doi.org/10.20546/ijcmas.2020.908.013 